Advances in Natural Sciences:

Nanoscience and Nanotechnology

PAPER

Antifungal applications for nano-additives synthesized with a bio-based approach

To cite this article: Erasmo Gámez-Espinosa et al 2020 Adv. Nat. Sci: Nanosci. Nanotechnol. 11015019

View the article online for updates and enhancements. 


\title{
Antifungal applications for nano-additives synthesized with a bio-based approach
}

\author{
Erasmo Gámez-Espinosa ${ }^{1}$, Leyanet Barberia-Roque ${ }^{1}$, \\ Olayide Folashade Obidi ${ }^{2}$, Cecilia Deyá ${ }^{1,3}$ and Natalia Bellotti ${ }^{1,4}$ \\ ${ }^{1}$ Centro de Investigación y Desarrollo en Tecnología de Pinturas (CONICET-CICPBA-UNLP), Buenos \\ Aires, Argentina \\ ${ }^{2}$ University of Lagos, Nigeria \\ ${ }^{3}$ Facultad de Ingeniería - Universidad Nacional de La Plata, Buenos Aires, Argentina \\ ${ }^{4}$ Facultad de Ciencias Naturales y Museo - Universidad de La Plata, Buenos Aires, Argentina \\ E-mail: n.bellotti@cidepint.ing.unlp.edu.ar
}

Received 21 October 2019

Accepted for publication 30 December 2019

Published 30 March 2020

\begin{abstract}
Filamentous fungi are microorganisms that cause deterioration of structural materials due to their ecological plasticity and vegetative functions. Functionalised sol-gel based products can be used to control this kind of biodeterioration through the association to antifungal active additives which are trapped in the siloxane crosslinking. Bioactive additives and materials to control microbial growth have been gaining more attention over the years. However, due to the concern about their toxicity, bio-based approach has been explored. The aim of the present research was to obtain antifungal additives with nanoparticles synthesised with aqueous extract of Senna occidentalis $\mathrm{L}$ and silver or copper salts to obtain a functionalised sol-gel based product to control the biodeterioration of bricks. Nanoparticles were characterised by UV-vis spectroscopy, transmission electron microscopy and x-ray diffraction. Silver nanoparticles $(15 \mathrm{~nm})$ showed higher stability over time and proved to be active against Aspergillus versicolor and Cladosporium cladosporioides which were isolated from brick wall. The strains were selected due to their high frequency in mycobiota of biodeteriorated structural building materials. The silver nanoparticles were successfully integrated in a silane-based matrix to be applied in bricks. The samples were characterised by surface tension determination, contact angle measurement, water absorption determination, scanning electron microscopy and energy dispersive $\mathrm{x}$-ray spectroscopy. Bricks with the lower concentration (2\%) of the functionalised silane (3mercaptopropyltrimethoxy) showed to be efficient to prevent fungal biofilm development with $100 \%$ of inhibition against both strains.
\end{abstract}

Supplementary material for this article is available online

Keywords: functional coating, nanoparticle, green synthesis, antifungal additive, biodeterioration Classification numbers: $2.04,4.02$

\section{Introduction}

Fungi, bacteria, algae and lichens manage to grow on building materials causing deterioration thereof [1, 2]. Moulds are among the microorganisms that cause the most deterioration due to their ecological plasticity. Their invasive growth which causes mechanical damage to the material, the absorptive heterotrophic nutrition with release of exoenzymes and the secretion of organic acids are their main deteriorating attributes [3]. Biodeterioration not only causes economic damage, but it can also affect the health of immunosuppressed people exposed to bioaerosols in contaminated indoor environments [4]. In this sense, additives applied at low concentrations in functional materials to control microbial colonisation in buildings are being studied [5].

Bioactive additives and materials as well as the methods to obtain them have been gaining more attention over the years due to the concern related to their toxicity and 
environmental impact. At present, eco-friendly variants like biogenic compounds or their derivatives are intensively studied [6-8]. Therefore, from the emergence of a greater awareness in relation to practices and methodologies, green chemistry approach was promising for the obtaining of bioactive materials [9]. In this regard, bio-based synthesis of nanoparticles (NPs) have been explored and the use of aqueous plant extracts presents advantages such as lower production costs, devoid of harmful chemicals, uses of renewable reagents and accessible to scale-up production [10, 11]. Antifungal activity of Ag NPs integrated in polymers for food industrial application has been corroborated for the control of Fusarium spp and their main associated mycotoxins [12]. A possible mechanism of action against fungi suggested that due to their small size nanoparticles can easily penetrate the cell wall and reach the membrane where they interact with fungal protein which leads to interference with their functionality [13]. Plant extracts contain a wide range of metabolites that would act as reducing and stabilising agents. Although the mechanisms are not entirely elucidated, different studies indicate that proteins, flavonoids, polyphenols, alkaloids, and terpenoids would play a role in the synthesis of metal nanoparticles [14].

The aim of the present research was to obtain antifungal nano-additives using aqueous extract from $S$. occidentalis leaves and metal salts to integrate in a silane matrix to prevent fungal biofilm development in bricks. The strains used in the bioassays were isolated and selected due to their frequency in the environment and the mycobiota developing on bricks in La Plata city. $S$. occidentalis is a small shrub about $3 \mathrm{ft}$ with lanceolate or ovate-lanceolate leaves usually found in America, Australia and Africa [15]. Since ancient times people around the world use plants in traditional medicines for the treatment of a variety of diseases [16]. The use of solgel in the protection of different substrates is on the basis that they change the superficial properties of the materials often due to the addition of an active agent that is trapped in the siloxane network [17].

The assessment of bioactivity of the nanoparticle's suspensions obtained and functionalised coatings was carried out by conventional agar plate assays. The strains used were isolated from biodeteriorated structural materials. Different techniques were used in the characterisation of the nanoparticles: UV-vis spectroscopy, transmission electron microscopy (TEM) and x-ray diffraction (XRD). The bricks samples were characterised by scanning electron microscopy (SEM), TEM and energy dispersive x-ray spectroscopy (EDS). In addition to this, the determination of surface tension, contact angle and water absorption was performed.

\section{Materials and methods}

\subsection{Bio-based synthesis and characterisation of nanoparticles}

Fresh leaves were bought from local herb sellers at Bariga Market in Lagos State, Nigeria, and identification of the specimens was corroborated by A Kadiri, a taxonomist from the Department of Botany, University of Lagos. S. occidentalis leaves were dried and milled. The phytochemicals (tannins, saponins, phlobatannins, flavonoids, alkaloids, terpenoids and glycosides) found in the plant extract obtained as described by Edeoga et al were determined [18]. The screening was based on the procedure followed by $\mathrm{R} \mathrm{O}$ Akinyeye and Olatunya, 2014 [19].

Aqueous extract of $S$. occidentalis was used in the synthesis of the nano-additives [20]. Briefly, $20 \mathrm{~g}$ of dried plant was used and added to $200 \mathrm{~mL}$ of distilled water (DW) and extracted for $3 \mathrm{~min}$ at $80{ }^{\circ} \mathrm{C}$. The NPs were obtained by mixing the extract and the salt aqueous solution $\left(\mathrm{AgNO}_{3}\right.$ or $\left.\mathrm{Cu}\left(\mathrm{NO}_{3}\right)_{2} \cdot 3 \mathrm{H}_{2} \mathrm{O}\right)$ at $60{ }^{\circ} \mathrm{C}$ in constant agitation during $30 \mathrm{~min}$. The final concentrations were $10^{-2} \mathrm{M}$ and $10^{-3} \mathrm{M}$ for both salts. The $\mathrm{pH}$ was adjusted to 7 by $\mathrm{NH}_{4} \mathrm{OH}$ solution. The suspensions were kept in the refrigerator at $4{ }^{\circ} \mathrm{C}$ [21].

The stability in time of these suspensions was evaluated by means of UV-vis spectroscopy carried out 1, 30 and 90 days after the synthesis. The measurements were made in a UV SP 2000 spectrophotometer. The presence of the nanoparticles was confirmed and their morphology was observed by TEM. The equipment used was a JEOL $100 \mathrm{CXII}$ at an acceleration voltage of $100 \mathrm{kV}$. The nanoparticles in suspension were centrifuged and washed through a DLAB D3024R microcentrifuge at $15000 \mathrm{rpm}$ during $20 \mathrm{~min}$ at $20{ }^{\circ} \mathrm{C}$ to be purified [22]. The purified nanoparticles were subjected to XRD using a Vertical Goniometer Diffractometer, Theta-Theta, Wide Angel Goniometer D/Max-C and sweep range between $5^{\circ}-90^{\circ}$.

\subsection{Selection of fungal strains: molecular analysis and identification}

The strains used for the bioassays were isolated from biodeteriorated bricks located in the city of La Plata $\left(34^{\circ} 54^{\prime} \mathrm{S}\right.$ and $57^{\circ} 55^{\prime} \mathrm{W}$ ) by swab technique [21]. They were identified at the species level based on their micro and macrostructure using standard taxonomic keys [23]. The reproductive and vegetative structures were observed by optical microscopy. Taxonomic identification was confirmed by molecular methods based on the analysis of sequences coding for $18 \mathrm{~S}$ ribosomal RNA. The sequences were amplified ITS (internal transcribed spacer) through PCR (polymerase chain reaction) and then, they were sequenced and analysed [21]. The primers used were ITS 1 (5'-TCC GAT GGT GAA CCT GCG G-3') and ITS4 (5'-TCC TCC GCT TAT TGA TAT GC-3'). This procedure was carried out through the company Macrogen (www.macrogenlatam.com.ar). The strains were selected due to their high frequency.

\subsection{Antifungal activity of nano-additives}

The effect of nanoparticle suspensions obtained was studied on spore germination by 48-well plate assay [24]. In the well spore $\left(10^{5}\right.$ spores $\left./ \mathrm{ml}\right)$, liquid Czapek medium and nanoparticle suspensions were mixed. In the final dilutions the concentration of nanoparticles was $0.5,0.3,0.1$ and $0.01 \mathrm{mg} \mathrm{ml}^{-1}$. For the positive control, the nanoparticles were 
replaced with cetrimide $\left(30 \mathrm{mg} \mathrm{ml}^{-1}\right)$ and a spore solution with liquid Czapek was used as a negative control. The plates were maintained at $28^{\circ} \mathrm{C}$ for $24 \mathrm{~h}$. The assay was carried out in triplicate. The percentage of inhibition of germination was calculated from the following equation:

$$
I G(\%)=\frac{C G}{T C} \times 100
$$

where $I G$ is percentage of inhibition of germination, $C G$ is the number of conidia without germinating and $T C$ is the total of conidia (200).

The effect of nanoparticle suspensions was studied on the mycelial growth by diffusion method in agar (Kirby-Bauer) [25]. In Petri dishes, $15 \mathrm{ml}$ of Malt Agar Extract (MEA) was inoculated with $200 \mu \mathrm{l}$ of spore suspension $\left(10^{5}\right.$ spores $\left.\mathrm{ml}^{-1}\right)$. Then, paper discs with a diameter of $6 \mathrm{~mm}$ embedded in the nanoparticles' suspensions were placed on inoculated MEA. As a negative control, physiological solution $(0.85 \mathrm{~g}$ of $\mathrm{NaCl} /$ $100 \mathrm{ml}$ of sterile DW) was used and the positive control was a quaternary amine solution with known antifungal activity $\left(3 \mathrm{mg} \mathrm{ml}^{-1}\right)$. The Petri dishes were incubated at $28^{\circ} \mathrm{C}$ for $48 \mathrm{~h}$. After that time the diameter of the inhibition halo $(D)$ was measured with Electronic Digital Caliber, whose precision is $0.01 \mathrm{~mm}$. $D<6 \mathrm{~mm}$ was considered without antifungal activity and $D \geqslant 6 \mathrm{~mm}$ with antifungal activity. The nanoparticle suspensions that showed higher antifungal activity were selected to be integrated in the sol-gel coatings in the next step.

\subsection{Brick treatments with the nano-additives: preparation and characterisation}

Commercial brick used in the present research work was characterised by determining water absorption, density and porosity, following the procedure of the IRAM 12588, IRAM 12593 and ASTM C642 standards, respectively.

Two silane precursors were used for the brick treatments: 3-Aminopropyl triethoxysilane (AMEO) and 3-Mercaptopropyltrimethoxysilane (MTMO) (Camsi-X, used as supplied). In this formulation, each silane was added at 4 and $2 \%$. The amount of corresponding silane was added under constant stirring to a solution containing $0.9 \mathrm{ml} \mathrm{ml}^{-1}$ of ethanol and $0.06 \mathrm{ml} \mathrm{ml}^{-1}$ of nanoparticle's suspensions, $\mathrm{pH}$ was previously adjusted to 4 with $\mathrm{HNO}_{3}$. In the case of the $2 \%$ solution, $2 \%$ of distilled water was added. Controls, where the same volume of nanoparticles in suspension was replaced by DW, were also prepared. After $1 \mathrm{~h}$ of hydrolysis, bricks of $4.0 \pm 0.4 \mathrm{~cm}^{3}$ were immersed in the solutions for $90 \mathrm{~s}$ and allowed to dry for 14 days at $25^{\circ} \mathrm{C}$. After 14 days of drying the antifungal activity of the brick samples was evaluated.

The treated and untreated bricks were observed by SEM. EDS analysis and x-ray mapping were performed too. The microscope was a Philips FEI Quanta 200, and the working conditions were low vacuum $\left(10^{-2}\right.$ torr). To analyse the degree of silane penetration in the treated bricks by SEM and EDS, crosscuts were done and the cross sections were observed.
In addition to this, surface tension, contact angle and water absorption were determined [26]. The surface tension was evaluated by placing a drop of ethanol $96 \%$ solution, distilled water, and different solutions of ethanol 96\%/water on the samples. The absorption of the drop was observed by unaided eye. The surface tension was approximated by the surface tension of the more concentrated ethanol 96\%/water solution that did not wet the surface of the samples. The surface tension of the ethanol $96 \%$ /water solutions was determined by the Du Noüy tensiometer. The contact angle was measured by placing a drop of distilled water on the coated brick by a Pasteur pipette. A picture of the drop was taken by a Gaosuo digital microscope and the contact angle was measured by the Gaosuo software. Dried brick samples, previously weight in an analytical balance, were placed in a $100 \%$ humidity chamber and the gain of weight was determined during $102 \mathrm{~h}$ in order to determine the water absorption. In every case, the assays were done in triplicate and the untreated bricks were used as controls.

\subsection{Fungal resistance assay}

Brick samples were previously sterilised and then treated as detailed above to be used in the bioassay. The fungal strains were the same as used before. The treated and untreated bricks were placed in Petri dishes with $10 \mathrm{ml}$ of Minimum Mineral Agar (MMA). Each brick was inoculated with $50 \mu \mathrm{l}$ of spore solution $\left(10^{5}\right.$ spores $\left./ \mathrm{ml}\right)$. The Petri dishes were incubated at $28{ }^{\circ} \mathrm{C}$ for 30 days [20, 21]. For each treatment, 6 samples were tested. The fungal growth observed in the bricks was reported as the percentage (\%) of the covered area and was rated based on the ASTM 5590 standard.

At the end of the trial, the samples were observed by a stereoscopic microscope, Leica S8 APO, and photographic records were taken by Leica digital camera. In addition, the brick samples were observed by SEM. The working conditions were low vacuum because in this operation mode the samples did not require being dehydrated, which allowed keeping more natural morphology of the fungal biofilm.

\section{Results and discussion}

\subsection{Bio-based synthesis and characterisation of nanoparticles}

The phytochemical screening of $S$. occidentalis extract allowed detecting the presence of tannins, saponins, flavonoids, alkaloids and terpenoids. This agrees with previous research of Odeja et al, which reported antimicrobial and antioxidant activities of phytoconstituents in S. occidentalis extract [15]. These biogenic compounds would be involved in the reduction and stabilisation of nanoparticles [27, 28]. Taking into account these results and Pal et al analysis of the alcoholic extract of $S$. occidentalis which showed the presence of several flavonoids such as $3^{\prime}, 4^{\prime}, 7$-trihydroxy-flavone, luteolin, and apigenin, a possible mechanism for the reduction of $\mathrm{Ag}^{+}$is proposed in figure $\mathrm{S} 1$ of supplementary material available online at stacks. iop.org/ANSN/11/015019/mmedia (by the example of 

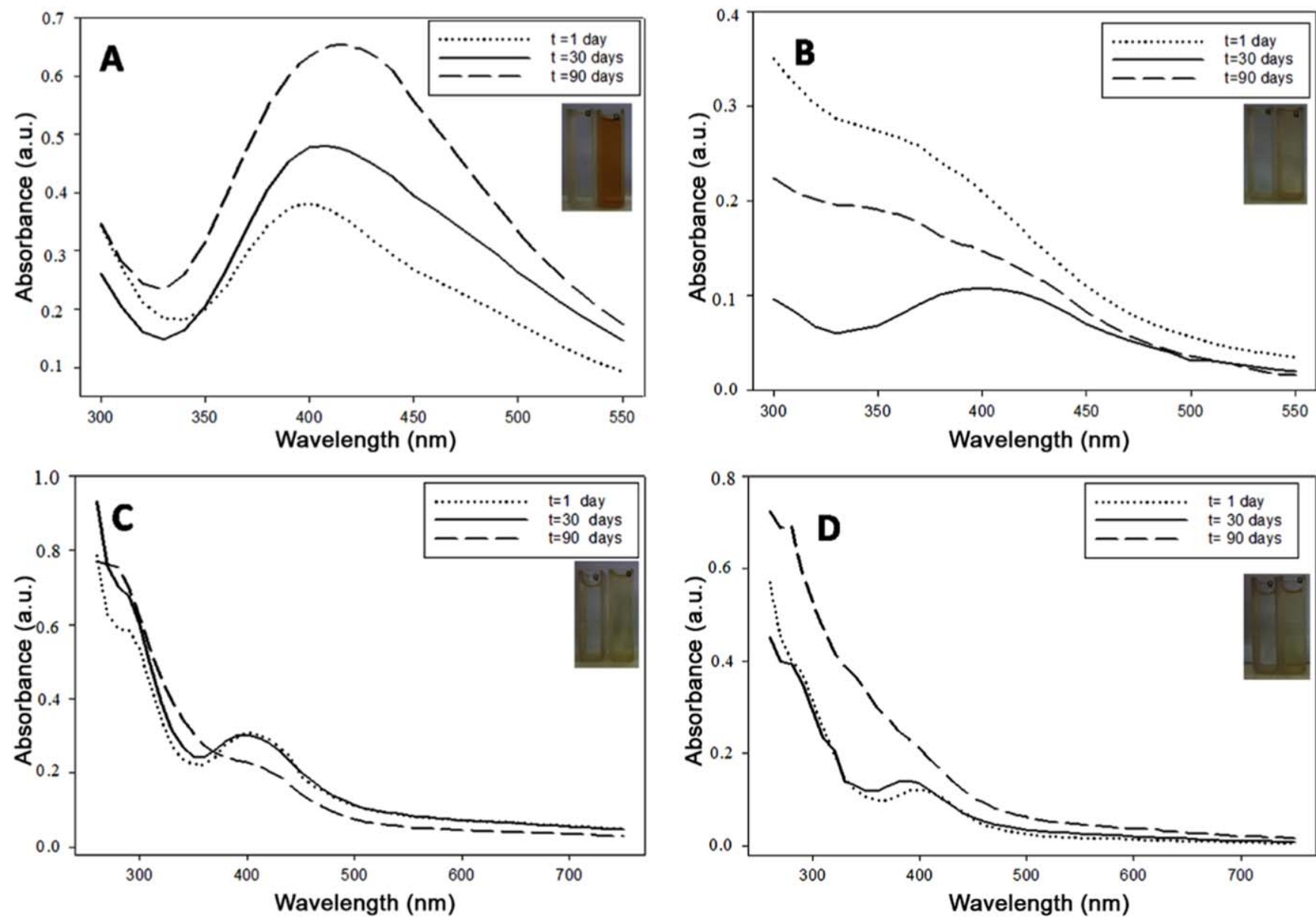

Figure 1. UV-vis absorption spectra of the nanoparticles in suspension obtained from S. occidentalis: (A) AgNPs2, (B) AgNPs3, (C) CuNPs2 and (D) CuNPs3.

$3^{\prime}, 4^{\prime}, 7$-trihydroxy-flavone) [29]. In this scheme, $\mathrm{Ag}^{+}$ions form intermediate complexes with hydroxyl groups of the flavonoid, which is oxidised with the consequent reduction of the silver ions to $\mathrm{Ag}^{\circ}$ [30]. This matches with different studies which proposed flavonoids and polyphenols as possibly responsible for Ag NPs synthesis and stabilisation [31-33].

Figure 1 shows the UV-vis absorption spectra of the nanoparticles in suspension. The nanoparticles synthesised with $\mathrm{AgNO}_{3} \quad 10^{-2} \mathrm{M}$ (AgNPs2) and $\mathrm{AgNO}_{3} \quad 10^{-3} \mathrm{M}$ (AgNPs3) showed a maximum absorption peak between $400-410 \mathrm{~nm}$ after $24 \mathrm{~h}$. The appearance of these absorption bands is a characteristic of the nanoparticles due to surface plasmon resonance (SPR) [34]. In the case of AgNPs2 sample, the peak remained stable although it increased in intensity during time, which could be due to the increase in the number of particles (figure 1(A)). The AgNPs3 sample did not show a defined and stable band during time (figure 1(B)). In the case of nanoparticles synthesised with the $\mathrm{Cu}\left(\mathrm{NO}_{3}\right)_{2} \cdot 3 \mathrm{H}_{2} \mathrm{O} 10^{-2} \mathrm{M}$ (CuNPs2) and $\mathrm{Cu}\left(\mathrm{NO}_{3}\right)_{2} \cdot 3 \mathrm{H}_{2} \mathrm{O} 10^{-3} \mathrm{M}$ (CuNPs3), the maximum absorption peak at $\sim 400 \mathrm{~nm}$ was more defined and intense in the case of the first one. These bands would correspond with cuprous oxide plasmonic ones and remain stable for 30 days (figures $1(\mathrm{C})$ and (D)) [28]. However, it was not stable for longer time.
TEM images confirmed the presence of nanoparticles and micrographs obtained from AgNPs2 and CuNPs2 suspensions are shown in the figures 2(A)-(E). AgNPs2 presented a quasispherical shape with average size of $15 \mathrm{~nm}$ and the highest frequency size was between 10-20 nm (figure 2(C)) which was lower than CuNPs2. These results match with those presented in publications related to the green synthesis of silver nanoparticles [27, 34]. CuNPs2 (figure 2(F)) presented an average size of $24 \mathrm{~nm}$ with highest frequency between $10-40 \mathrm{~nm}$. The particles observed correspond mostly with truncated cube shape [28]. TEM images revealed that the particles are covered by a layer that would correspond with organic matter from plant extract that could help to keep them stable and dispersed.

The suspension obtained from $\mathrm{AgNO}_{3} 10^{-2} \mathrm{M}$ and the plant extract presented the surface plasmon resonance (SPR) absorption $\sim 405 \mathrm{~nm}$ confirming the presence of AgNPs which showed to be the most stable over time and presented the smaller average size. Therefore, AgNPs2 suspension was selected to continue with the present research work.

Analysis of AgNPs2 using XRD confirmed the crystalline nature of particles (figure 2(G)). A number of Bragg reflections with $2 \theta$ values of around $38.0^{\circ}, 46.1^{\circ}, 64.5^{\circ}$ and $77.4^{\circ}$ corresponding to the (111), (200), (220) and (311) set of lattice planes are observed which may be indexed as the band 


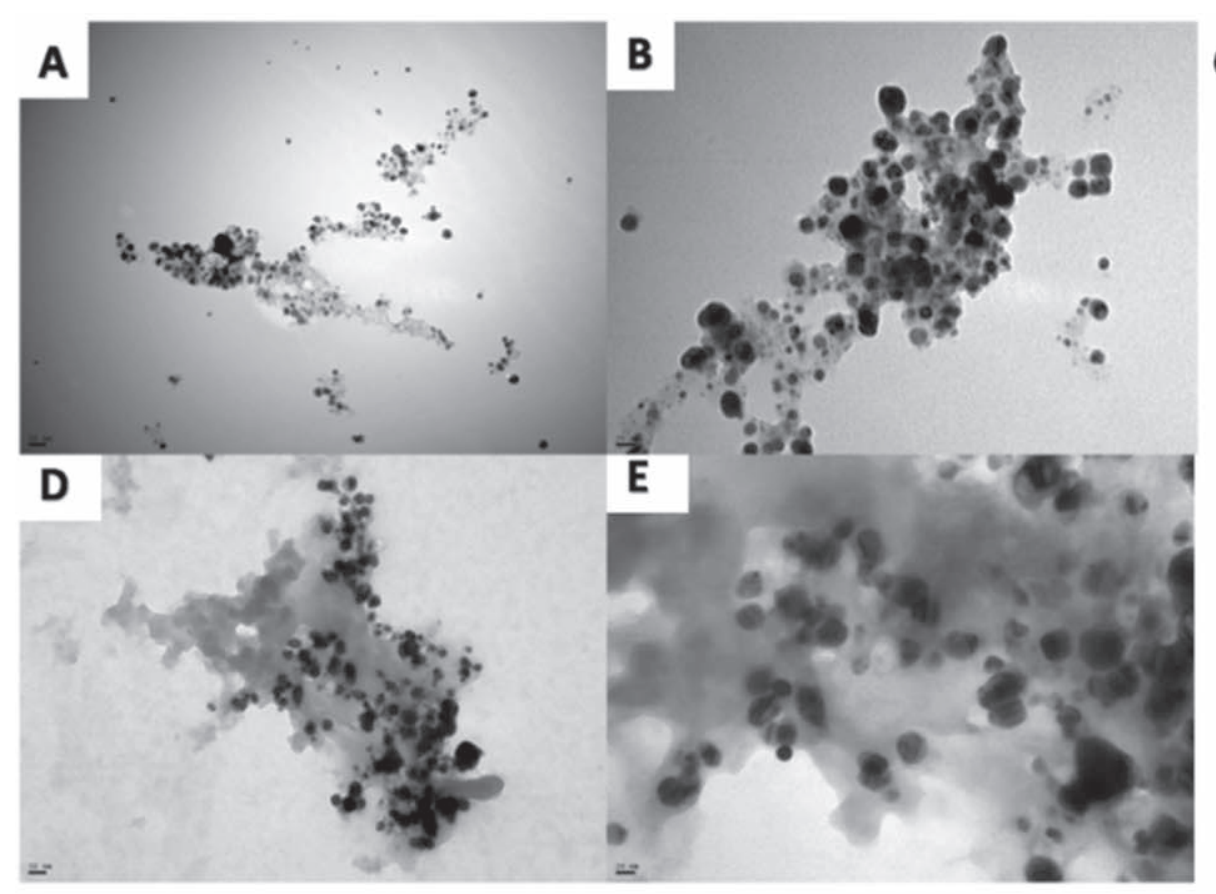

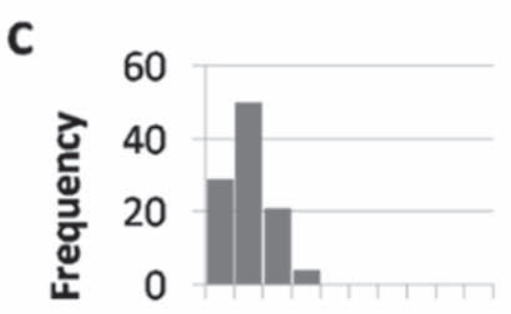

525456585 Particle size (nm)

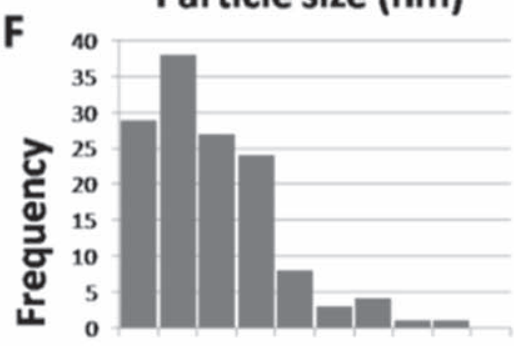

$5 \quad 152535455565758595$

Particle size (nm)

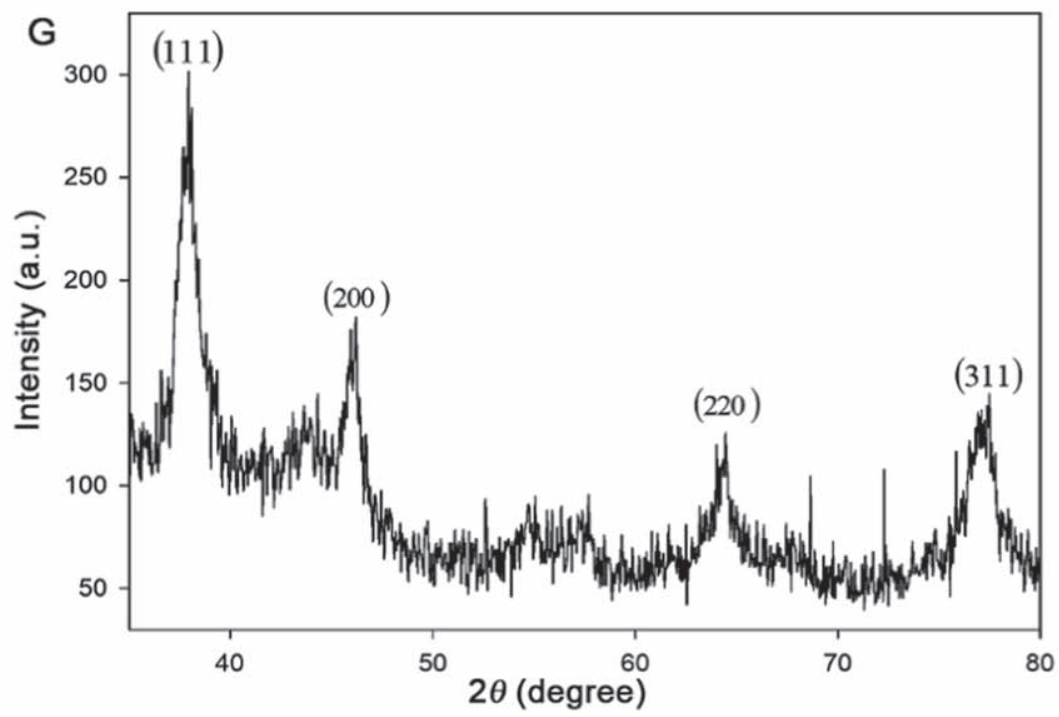

Figure 2. TEM images and histogram from size distribution analysis (A)-(F): AgNPs2 (A)-(C) and CuNPs2 (D)-(F). Magnification of A and D 100000x, B and E 270000x. The bar in each micrograph corresponds to $20 \mathrm{~nm}$. X-ray diffractogram of AgNPs 2 synthesised with S. occidentalis $(\mathrm{G})$.

for face centred cubic structure of silver (JCPDS, \# 4-0783). The XRD pattern showed that the AgNPs2 formed by the reduction of $\mathrm{Ag}^{+}$ions are crystalline in nature and similar to earlier published results [34]. The unassigned peaks could be due to the crystallisation of organic phase that occurs on the surface of the nanoparticle.

\subsection{Selection of fungal strains: molecular analysis and identification}

The sequences obtained were analysed by means of the genetic data bank (www.ncbi.nlm.nih.gov/blast/Blast.cgi) using a search and sequence analysis software (Blast searches) to find the closest known analogues. In this sense, the isolated strains identified using GenBank database and the corresponding ITS sequences were Aspergillus versicolor and Cladosporium cladosporioides. These results were supported by morphological analysis. Sequences have been deposited in GenBank database and the accession numbers MG725821 and MG731215 were assigned to A. versicolor and C. cladosporioides, respectively.

\subsection{Antifungal activity of the nano-additive selected}

The antifungal activity of the AgNPs2 suspension was confirmed in the germination inhibition test where a direct relationship between the concentration and the inhibition of germination of conidia of both strains was observed (figure S2A of supplementary material). Regarding C. cladosporioides, the percentages of inhibition were higher than with 

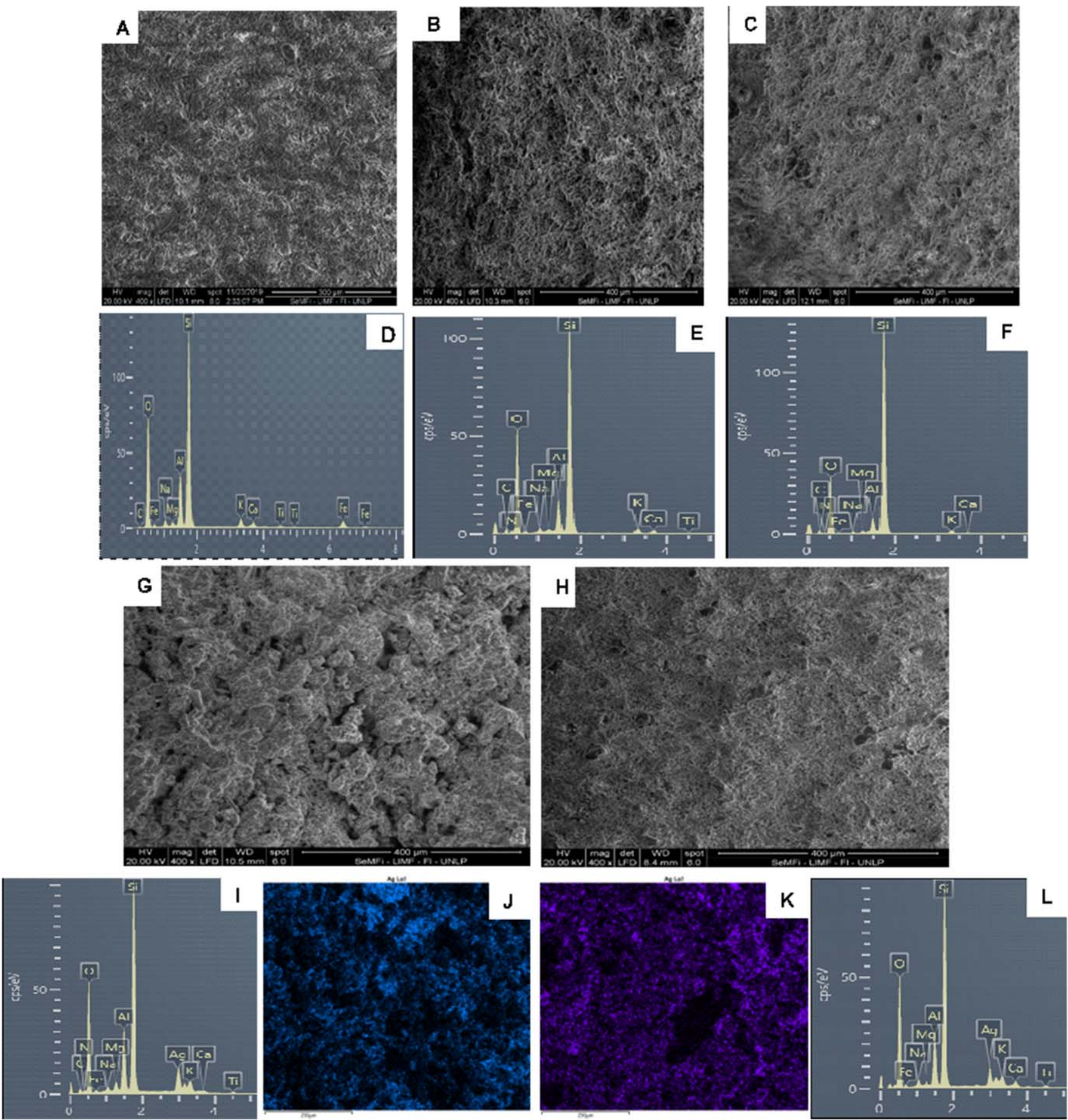

Figure 3. SEM micrographs and EDS spectra: (A) and (D) untreated brick; (B) and (E) AMEO 4\%; (C) and (F) AMEO 2\%; (G) and (I) AMEO 4\%+ AgNPs2; (H) and (L) AMEO 2\%+ AgNPs2; (J) and (K) Ag mapping.

A. versicolor. When the concentration of AgNPs2 sample was $0.5 \mathrm{mg} \mathrm{ml}^{-1}$, there was an inhibition of germination of $98 \%$ against $C$. cladosporioides while with $A$. versicolor it was $85 \%$, which indicates greater sensitivity in the conidia of $C$. cladosporioides to AgNPs2. During the formation of the germinative tube, the wall of the hypha is thinner and fragile in the apical part, this may be the moment that allows the interaction of AgNPs2 in the cell wall, causing an increase in the permeability of the membrane and an alteration in conidial viability [35].

In the agar diffusion test (figure S2B of the supplementary material), the antifungal activity of AgNPs2 was reaffirmed against the studied strains. Inhibition halo diameters greater than $6 \mathrm{~mm}$ were observed. The average diameter of the inhibition halo in $C$. cladosporioides was higher than in $A$. versicolor, confirming the higher sensibility of the first one. 

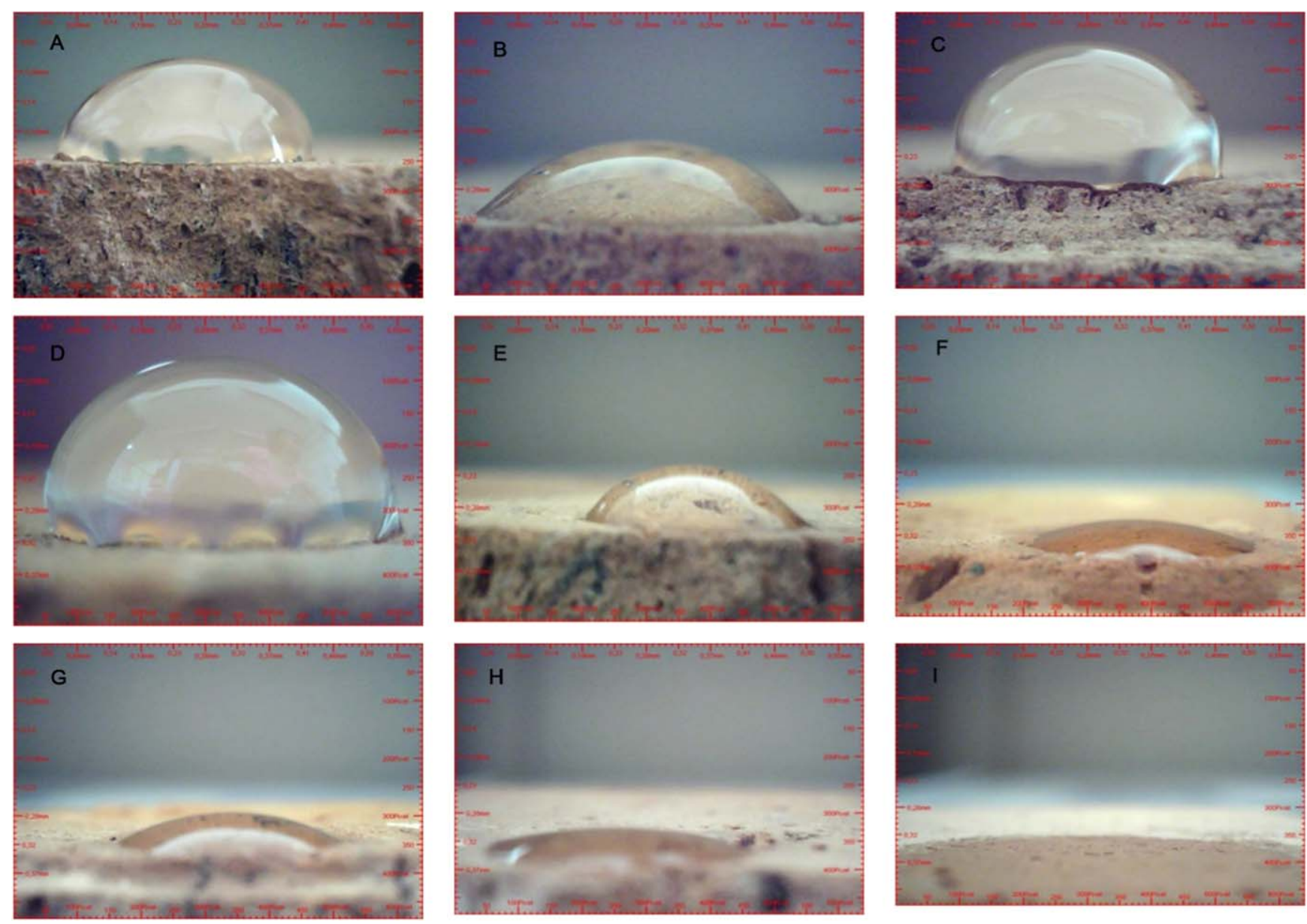

Figure 4. Water contact angle on samples with (A)-(I): MTMO 4\% (A); MTMO 4\%+AgNPs2 (B); MTMO 2\% (C); MTMO 2\%+AgNPs2 (D); AMEO 4\% (E); AMEO 4\%+ AgNPs $2(\mathrm{~F})$; AMEO 2\% (G); AMEO 2\%+ AgNPs2 (H) and without treatment (I).

Table 1. Fungal growth rating according to the area covered.

\begin{tabular}{lll}
\hline Brick treatments & A. versicolor & C. cladosporioides \\
\hline Control (without treatment) & 4 & 4 \\
MTMO 4\% & $3 / 4$ & $3 / 4$ \\
MTMO 4\%+AgNPs2 & $3 / 4$ & $3 / 4$ \\
MTMO 2\% & 3 & 3 \\
MTMO 2\%+AgNPs2 & 2 & 3 \\
AMEO 4\% & 3 & 0 \\
AMEO 4\% + AgNPs2 & $2 / 3$ & 0 \\
AMEO 2\% & 3 & 0 \\
AMEO 2\%+ AgNPs2 & 0 & 0 \\
\hline
\end{tabular}

Note: 0 (none $0 \%$ ), 1 (growth in traces $<10 \%$ ), 2 (light growth $10 \%-$ $30 \%$ ), 3 (moderate growth $30 \%-60 \%$ ) and 4 (heavy growth $60 \%-100 \%$ ).

Possibly the antifungal mechanisms of the AgNPs once they have been internalised by the apical end of the growing hypha, are the strong interaction of these NPs with nucleophiles such as amino and thiol groups inactivating enzymes and affecting processes such as nutrition and cellular respiration. Published data point out that silver ions can cause denaturation of proteins and DNA, which affects the replicative machinery in the fungal cell [36]. In addition to this, NPs can also generate reactive oxygen species that have a high cytotoxic activity and can cause cell death [31].

\subsection{Bricks characterisation}

The characterisation of the commercial untreated brick used was performed and water absorption, density and porosity were determined: $21.9 \pm 1.2 \%, \quad 1.40 \pm 0.03 \mathrm{~g} \mathrm{~cm}^{-3}$ and $30.9 \pm 0.8 \%$, respectively. Papers with similar values have been reported. For example, Graziani et al 2016 explain the influence of total porosity $(36.65 \pm 0.65 \%)$ and surface roughness on the susceptibility of clay bricks to deterioration by microorganisms [37]. SEM micrograph presented in figure 3(A) shows surface appearance of the untreated brick. In the EDS spectrum (figure 3(D)), the major peaks of $\mathrm{Si}, \mathrm{Al}$ and $\mathrm{O}$ are observed at $1.7,1.5$ and $0.3 \mathrm{keV}$, respectively. A semi-quantitative analysis of this spectrum showed that the elements presented were $\mathrm{O}, \mathrm{Si}, \mathrm{Al}, \mathrm{Fe}, \mathrm{K}, \mathrm{Na}, \mathrm{Ca}, \mathrm{C}, \mathrm{Mg}$ and $\mathrm{Ti}$ and their weight was 48.77, 31.50, 7.95, 4.75, 2.15, 1.70, $1.24,0.82,0.61,0.50 \%$, respectively.

SEM micrographs of the treated bricks with AMEO in the figures 3(B) and (C) show a decrease in the roughness when the concentration of silane decreased. The EDS spectra of samples with AMEO showed the corresponded peak of $\mathrm{N}$ from silane amino groups at $0.4 \mathrm{keV}$ (figures $3(\mathrm{E})$ and $(\mathrm{F})$ ). The addition of the AgNps2 to the silane did not produce changes in the surface appearance of the samples (figures $3(\mathrm{G})$ and $(\mathrm{H})$ ). A peak of $\mathrm{Ag}$ was observed at 

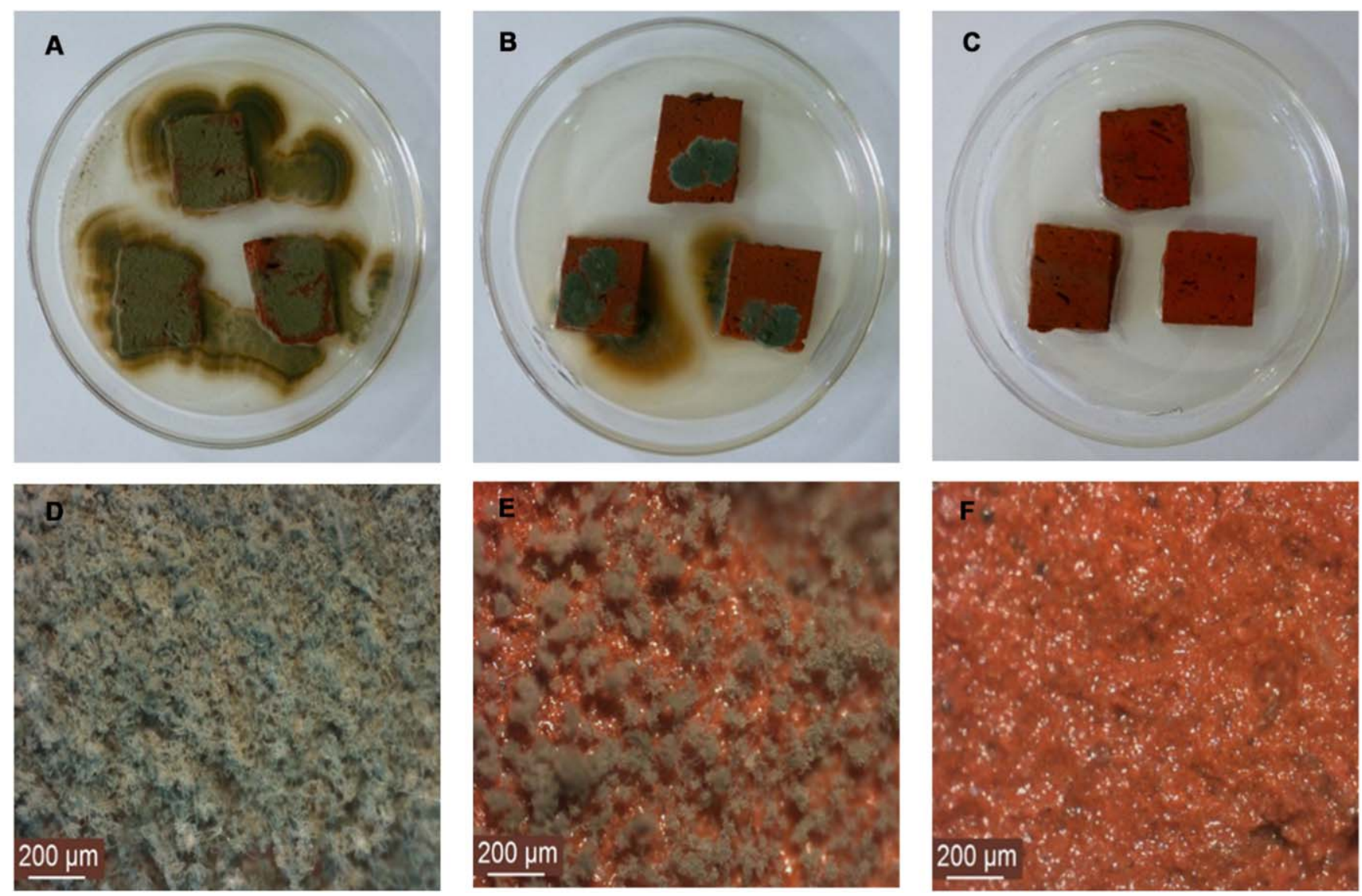

Figure 5. Fungal resistance test against A. versicolor, samples: control (untreated bricks) (A), (D); with AMEO 2\% (B), (E) and AMEO 2\%+ AgNPs2 (C, F). (D)-(F) were obtained from stereoscopic microscope $(80 \times)$.

$3 \mathrm{keV}$ in the EDS spectra of AMEO 4\%+AgNPs2 and AMEO 2\%+AgNPs2 (figures 3(I) and (L), respectively) samples where the Ag NPs were added. The mapping of Ag in figure $3(\mathrm{~J})$ and $(\mathrm{K})$ showed a homogeneous distribution of element on the surface of the brick, which reinforces the antifungal property in the whole material. This would be indicating that the Ag NPs were retained in the matrix during the drying of the sol-gel coating and they possibly interact with the amino groups of the silane. SEM micrographs from MTMO coatings presented a surface appearance similar to that observed in AMEO coatings.

The cross-sections obtained from treated bricks with AMEO and MTMO were evaluated in relation to the degree of penetration of silane in the material by SEM and EDS spectra analyses. In this sense, the presence of carbon was useful and EDS analysis was performed in different points of the cross-section of the samples (figures S3A and S3B of the supplementary material). The decrease in weight $\%$ of carbon between the edge and the inside of the material allows determining that the thickness of the treatment is $\sim 50-120 \mu \mathrm{m}$.

Images from water droplets on brick samples and the contact angle obtained are showed in the figures 4(A)-(I). In general, samples were hydrophilic except for those treated with MTMO 2\% and MTMO 2\% + AgNPs2 which presented water contact angle $>90^{\circ}$, classified as hydrophobic (figures 4(C) and (D)). AMEO 2\% +AgNPs2 showed the lower contact angle which it is related with a higher wettability (figure $3(\mathrm{H})$ ). All samples with AMEO (figures 4(E)(H)) were hydrophilic with water contact angles $<60^{\circ}$. The untreated brick immediately absorbs the drop of water when it is deposited on its surface as can be seen in the figure 4(I). Surface tension with ethanol/water solutions could only be measured in samples with MTMO due to its hydrophobic properties. In these cases, values of $61.3 \mathrm{dyn} \mathrm{cm}^{-1}$ were recorded.

The water absorption as a function of time of the brick samples treated and untreated was evaluated and presented in figures S4A and S4B of supplementary material. In general, the samples with AMEO absorbed more water than the corresponding ones with MTMO. This could be due to the strong affinity of the water for the amino groups. Bricks with MTMO absorbed less amount of water with respect to the control. A homogenous tendency was observed for all treated bricks, except for MTMO 2\% which absorbed much less water. Bricks with AMEO 4\% with and without AgNPs absorbed approximately the same amount of water as the control.

\subsection{Fungal resistance assay}

Table 1 shows the rating values assigned to the brick samples for each strain. The control was rated as 4 (heavy growth 60-100\%). The growth of C. cladosporiodes was classified as 

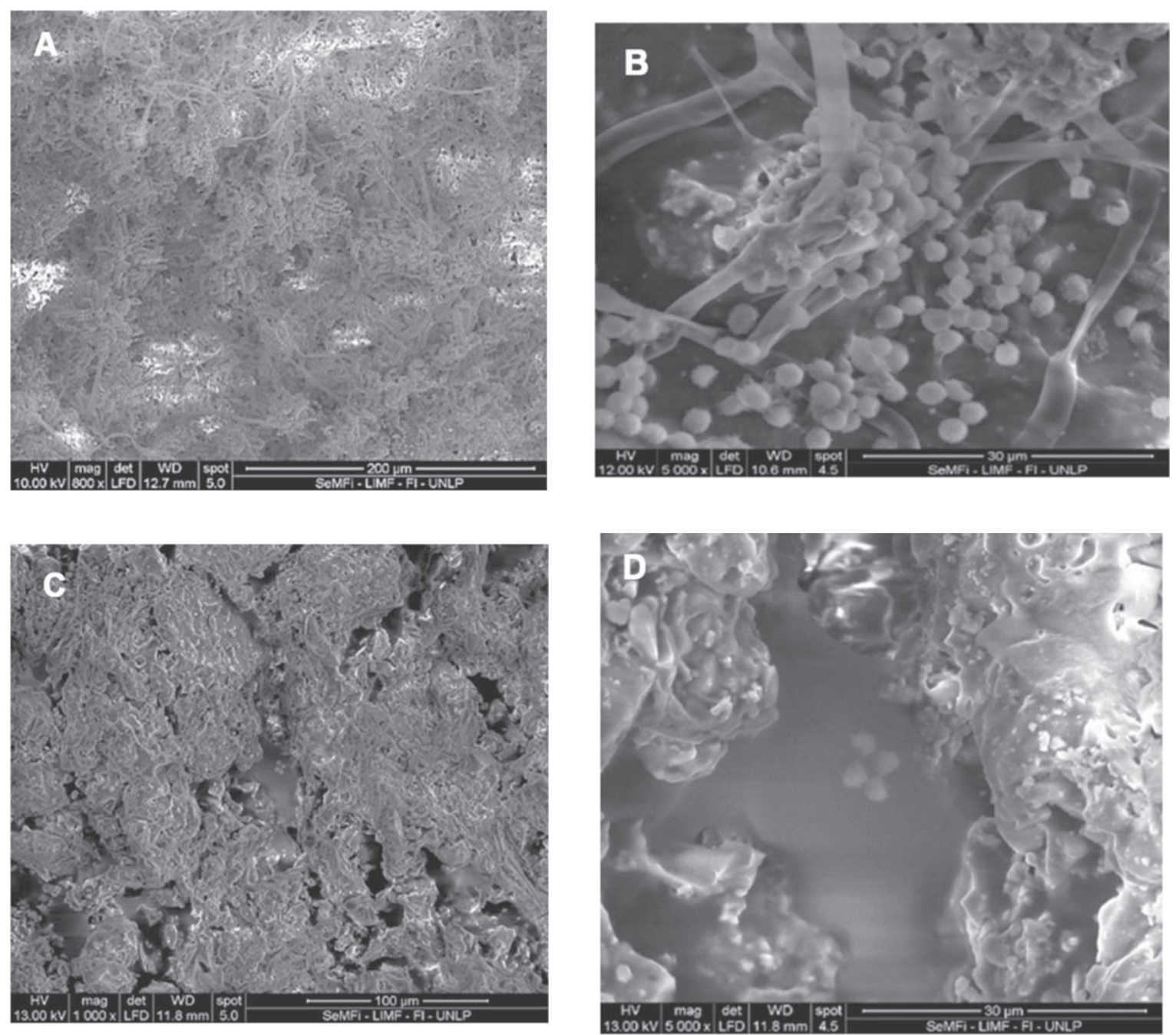

Figure 6. SEM images of fungal resistance test against A. versicolor: (A) AMEO 2\%; (B) detail of strain used; (C), (D) AMEO $2 \%+$ AgNPs2; (D) detail of nongerminated conidia.

0 (none $0 \%$ ) on all the coatings with AMEO. On the other hand, for A. versicolor 0 (none $0 \%$ ) was only achieved when it was exposed to AMEO $2 \%+$ AgNPs2, which confirmed the invasive growth of this strain and the higher sensibility of C. cladosporiodes. In coatings with MTMO $4 \%$ with or without Ag NPs the growth was similar to the control against both strains while in the case of the coatings with lower silane concentration the results improved to a moderate fungal development. The better results with this coating was obtained when the Ag NPs were present at the rating of 2 (light growth) against $A$. versicolor.

Figure 5 shows plates from the fungal resistance assay. On the untreated bricks, a biofilm capable of covering it completely was observed (figure 5(A)). On the brick with AMEO 2\%, isolated growth was observed (figure 5(B)). The resistance of sol-gel coatings with AMEO 2\% + AgNPs2 versus $A$. versicolor was optimal with a total inhibition of growth as it could be observed in the figure $5(\mathrm{C})$. These observations were corroborated by stereoscopic microscope which can be seen in figures 5(D)-(F). Although, AMEO 2\%, has a certain antifungal effect with respect to the control, no total inhibition was observed. This only occurred when AgNPs2 is present in the coating. The effectiveness of the coating with AMEO $2 \%+$ AgNPs2 compared to the respective one with MTMO could be related to the stronger interaction of the mercapto groups in MTMO with silver compared to amino groups in AMEO which may result in less availability for the interaction with fungal structures. These results are promising due to the low silver concentration $\left(10.8 \mathrm{mg} 100 \mathrm{ml}^{-1}\right)$ that it was required. There are research papers related to antimicrobial coatings formulated with AgNPs which report the achievement of an adequate biocidal activity with concentrations higher than $50 \mathrm{mg} 100 \mathrm{ml}^{-1}$ [38].

SEM micrographs of fungal resistance test against $A$. versicolor (figures $6(\mathrm{~A}),(\mathrm{B})$ ) showed a total inhibition of the germination of the spores, whereby no development of vegetative or reproductive mycelium was detected in the treated bricks which can be seen in figures $6(\mathrm{C})$ and (D). In addition to this a modified morphology of the inoculated spores exposed to the treated brick (figure 6(D)) can be seen when comparing with the spores observed in the untreated brick (figure 6(B)). These results agree with those obtained by 
Pinto et al for Aspergillus niger [39]. Previous research suggested that the hyphae and spore damage is probably associated to cell wall disruption which causes cell death, this effect has been more pronounced by increasing the Ag NPs content [40]. Similar results were obtained related to the antifungal activity against the other strain used ( $C$. cladosporiodes).

Antimicrobial surfaces are based on two main strategies: prevent the adherence of microorganisms or/and kill them on contact [41]. Taking into account the observations made in the present research work, the antifungal activity of the biosynthesised NPs in the treated bricks is based on their efficient contact with the fungal structures. It was proved that an efficient contact depends on the environment in which the nanoparticles are integrated besides the corresponding concentration [42]. This is consistent with the fact that treated bricks with a greater hydrophilicity (AMEO 2\% + AgNPs2) were more bioactive which could be related with the higher water content that favours the activity of the Ag NPs [43].

\section{Conclusion}

Senna occidentalis $L$. aqueous extract was useful for the obtaining of suspension of nanoparticles from silver and copper salts to be used as nano-additives. The suspension with silver nanoparticles showed inhibitory activity of germination and mycelial growth against both selected strains: $A$. versicolor and $C$. cladosporioides. Furthermore, it was possible to incorporate the nanoparticles in a functional sol-gel based matrix. In this sense, with the proposed methodology it was possible to achieve bricks with an efficient antifungal activity integrating directly the suspension of nanoparticles avoiding in this way any type of waste in the final product. This bio-based approach has important advantages as its economic viability and scaled up potentiality.

\section{Acknowledgments}

Authors are thankful for the essential support of: Consejo Nacional de Investigaciones Científicas y Técnicas (CONICET), Comisión de Investigaciones Científicas de la provincia de Buenos Aires (CICPBA), Agencia Nacional de Promoción Científica y Tecnológica (ANPCyT), Universidad Nacional de La Plata (UNLP) and Camsi-X. They also thank the technical support of the Ing. Pablo Bellotti and Ing. Pablo Seré.

\section{References}

[1] Özvan A, Dinçer I, Ak M, Oyan V and Tapan M 2015 Experimental studies on ignimbrite and the effect of lichens and capillarity on the deterioration of Seljuk Gravestones Eng. Geol. 185 81-95

[2] Li Q, Zhang B, Wang L and Ge Q 2017 Distribution and diversity of bacteria and fungi colonizing ancient Buddhist statues analyzed by high-throughput sequencing Int. Biodeterior. Biodegradation 117 245-54

[3] Fazio A T, Cavicchioli A, Penna D S A, Chambergo F S and De F D L A 2015 Towards a better comprehension of biodeterioration in earthen architecture: study of fungi colonisation on historic wall surfaces in Brazil J. Cult. Herit. 16 934-8

[4] Boral H, Metin B, Dö A, Seyedmousavi S and Ilkit M 2018 Overview of selected virulence attributes in aspergillus fumigatus, candida albicans, cryptococcus neoformans , trichophyton rubrum, and exophiala dermatitidis Fungal Genet. Biol. 111 92-107

[5] Falkiewicz-Dulik M, Janda K and Wypych G 2015 Handbook of Biodegradation, Biodetrioration and Biostabilization (Toronto: Chemtec Publishing)

[6] Hendessi S, Sevinis E B, Unal S, Cebeci F C, Menceloglu Y Z and Unal H 2016 Antibacterial sustainedrelease coatings from halloysite nanotubes/waterborne polyurethanes Prog. Org. Coatings 101 253-61

[7] Han Y, Yu M and Wang L 2018 Bio-based films prepared with soybean by-products and pine (Pinus densiflora) bark extract J. Clean. Prod. 187 1-8

[8] Jaiswal S, Bhattacharya K, Sullivan M, Walsh M, Creaven B S, Laffir F, Duffy B and McHale P 2013 Non-cytotoxic antibacterial silver-coumarin complex doped sol-gel coatings Colloids Surfaces B Biointerfaces 102 412-9

[9] Singh P, Kim Y, Zhang D and Yang D 2016 Biological synthesis of nanoparticles from plants and microorganisms Trends Biotechnol. 34 588-99

[10] Kumar P V, Jelastin S M and Prakash K S 2019 Journal of environmental chemical engineering green synthesis derived pt-nanoparticles using xanthium strumarium leaf extract and their biological studies J. Environ. Chem. Eng. 7 103146

[11] Mohamed H E A, Afridi S, Khalil A T, Zia D, Iqbal J, Ullah I, Shinwari Z K and Maaza M 2019 Biosynthesis of silver nanoparticles from Hyphaene thebaica fruits and their in vitro pharmacognostic potential Mater. Res. Express 6 $1050 \mathrm{c} 9$

[12] Tarazona A, Gómez J V, Mateo E M, Jiménez M and Mateo F 2019 Antifungal effect of engineered silver nanoparticles on phytopathogenic and toxigenic Fusarium spp. and their impact on mycotoxin accumulation Int. J. Food Microbiol. 306108259

[13] Ogar A, Tylko G and Turnau K 2015 Antifungal properties of silver nanoparticles against indoor mould growth Sci. Total Environ. 521-522 305-14

[14] Padalia H, Moteriya P and Chanda S 2015 Green synthesis of silver nanoparticles from marigold flower and its synergistic antimicrobial potential Arab. J. Chem. $8732-41$

[15] Odeja O, Obi G, Ogwuche C E, Elemike E E and Oderinlo Y 2015 Phytochemical screening, antioxidant and antimicrobial activities of senna occidentalis (L.) leaves extract Clin. Phytoscience 16

[16] Mujib T I A 2013 In vitro plant regeneration of coffee senna (Senna occidentalis) from hypocotyl-derived callus Acta Biol. Cracoviensia 55 120-5

[17] Stobie N, Duffy B, Mccormack D E, Colreavy J, Hidalgo M, Mchale P and Hinder S J 2008 Prevention of Staphylococcus epidermidis biofilm formation using a low-temperature processed silver-doped phenyltriethoxysilane sol-gel coating Biomaterials 29 963-9

[18] Edeoga H O and Okwu D E M B O 2005 Phytochemical constituents of some nigerian medicinal plants $A f r$. $J$. Biotechnol 4 685-8

[19] Akinyeye R O and Olatunya A M 2014 Phytochemical screening and mineral composition of the bark of some medicinal trees in Ondo state Nigeria Med. Aromat. Plant Res. J. 2 44-9 
[20] Barberia-Roque L, Gámez-Espinosa E, Viera M and Bellotti N 2019 Assessment of three plant extracts to obtain silver nanoparticles as alternative additives to control biodeterioration of coatings Int. Biodeterior. Biodegradation 141 52-61

[21] Deyá C and Bellotti N 2017 Biosynthesized silver nanoparticles to control fungal infections in indoor environments Adv. Nat. Sci.: Nanosci. Nanotechnol. 8 025005

[22] Arunachalam R, Dhanasingh S, Kalimuthu B, Uthirappan M, Rose C and Mandal A B 2012 Phytosynthesis of silver nanoparticles using Coccinia grandis leaf extract and its application in the photocatalytic degradation Colloids Surfaces B Biointerfaces 94 226-30

[23] Bensch K, Braun U, Groenewald J Z and Crous P W 2012 The genus cladosporium Stud. Mycol. 72 1-401

[24] Levinskaitė L 2012 Susceptibility of food-contaminating Penicillium genus fungi to some preservatives and disinfectants Annals of Agricultural and Environmental Medicine 19 85-9

[25] Fernández M A and Bellotti N 2017 Silica-based bioactive solids obtained from modified diatomaceous earth to be used as antimicrobial filler material Mater. Lett. 194 130-4

[26] Koch K and Barthlott W 2009 Superhydrophobic and superhydrophilic plant surfaces: an inspiration for biomimetic materials Philos. Trans. R. Soc. A Math. Phys. Eng. Sci. 367 1487-509

[27] Kouvaris P, Delimitis A, Zaspalis V, Papadopoulos D, Tsipas A and Michailidis N 2012 Green synthesis and characterization of silver nanoparticles produced using Arbutus Unedo leaf extract Mater. Lett. 76 18-20

[28] Shui A, Zhu W, Xu L, Qin D and Wang Y 2013 Green sonochemical synthesis of cupric and cuprous oxides nanoparticles and their optical properties Ceram. Int. 39 8715-22

[29] Pal S, Kumar P, Ramakrishna E, Kumar S and Porwal K 2019 Extract and fraction of Cassia occidentalis L. (a synonym of Senna occidentalis ) have osteogenic e ff ect and prevent glucocorticoid-induced osteopenia J. Ethnopharmacol. 235 8-18

[30] Terenteva E A, Apyari V V, Dmitrienko S G and Zolotov Y A 2015 Formation of plasmonic silver nanoparticles by flavonoid reduction: a comparative study and application for determination of these substances Spectrochim. Acta - Part A Mol. Biomol. Spectrosc. 151 89-95

[31] Rajeshkumar S and Bharath L V 2017 Mechanism of plantmediated synthesis of silver nanoparticles-A review on biomolecules involved, characterisation and antibacterial activity Chem. Biol. Interact. 273 219-27
[32] Bulut E 2009 Rapid, facile synthesis of silver nanostructure using hydrolyzable tannin Ind. Eng. Chem. Res. 48 5686-90

[33] Makarov V V et al 2014 'Green' nanotechnologies: synthesis of metal nanoparticles using plants Acta Naturae 6 35-44

[34] Raj S and Trivedi R 2018 Green synthesis and characterization of silver nanoparticles using Enicostemma axillare (Lam.) leaf extract Biochem. Biophys. Res. Commun. 503 2814-9

[35] Mahmoud M A, Eifan S A and Majrashi M 2014 Application of silver nanoparticles as antifungal and antiaflatoxin B1 produced by Aspergillus flavus Dig. J. Nanomater. Biostructures 9 151-7

[36] Dananjaya S H S, Erandani W K C U, Kim C, Nikapitiya C, Lee J and De Z M 2017 Comparative study on antifungal activities of chitosan nanoparticles and chitosan silver nano composites against Fusarium oxysporum species complex Int. J. Biol. Macromol. 105 478-88

[37] Graziani L, Quagliarini E and D'Orazio M 2016 The role of roughness and porosity on the self-cleaning and antibiofouling efficiency of $\mathrm{TiO}_{2}-\mathrm{Cu}$ and $\mathrm{TiO}_{2}-\mathrm{Ag}$ nanocoatings applied on fired bricks Constr. Build. Mater. 129 116-24

[38] Holtz R D, Lima B A, Filho A G S, Brocchi M and Alves O L 2012 Nanostructured silver vanadate as a promising antibacterial additive to water-based paints Nanomedicine Nanotechnology, Biol. Med. 8 935-40

[39] Pinto R J B, Almeida A, Fernandes S C M, Freire C S R, Silvestre A J D, Neto C P and Trindade T 2013 Antifungal activity of transparent nanocomposite thin films of pullulan and silver against Aspergillus niger Colloids Surfaces B Biointerfaces 103 143-8

[40] Gopinath V and Velusamy P 2013 Extracellular biosynthesis of silver nanoparticles using Bacillus sp. GP-23 and evaluation of their antifungal activity towards Fusarium oxysporum Spectrochim. Acta Part A Mol. Biomol. Spectrosc. 106 170-4

[41] Děkanovský L, Elashnikov R, Kubiková M, Vokatá B, Švorčík V and Lyutakov O 2019 Dual-action flexible antimicrobial material: switchable self-cleaning, antifouling, and smart drug release Adv. Funct. Mater. 291901880

[42] Elashnikov R, Lyutakov O, Kalachyova Y, Solovyev A and Svorcik V 2015 Tunable release of silver nanoparticles from temperature-responsive polymer blends React. Funct. Polym. 93 163-9

[43] Dominguez-Wong C, Loredo-Becerra G M, Quintero-González C C, Noriega-Treviño M E, Compeán-Jasso M E, Niño-Martínez N, Dealba-Montero I and Ruiz F 2014 Evaluation of the antibacterial activity of an indoor waterborne architectural coating containing $\mathrm{Ag} / \mathrm{TiO}_{2}$ under different relative humidity environments Mater. Lett. 134 103-6 